\title{
Schneeglöckchen im Herbst
}

\author{
Martin Börnchen
}

\begin{abstract}
In contrast to the commonly known snowdrops which flower from late winter to spring, Galanthus reginae-olgae blooms during autumn. There are also Crocus species blooming in autumn or in spring. It is briefly introduced as a fall-flowering snowdrop.
\end{abstract}

\section{Zusammenfassung}

Innerhalb der Schneeglöckchen gibt es einige Arten, die im Herbst blühen statt zur üblichen Blütezeit im ausklingenden Winter und Frühling. Auch bei den Krokussen gibt es Herbst- und Frühjahrsblüher. Galanthus reginae-olgae wird als herbstblühendes Schneeglöckchen kurz vorgestellt.

\section{Blüten im Herbst und im Frühling}

Im ausklingenden Sommer oder Herbst denken viele Pflanzenfreunde längst noch nicht daran, in Gärten nach den ersten Schneeglöckchen oder Krokussen Ausschau zu halten, müssen doch erst nach einer Kälteperiode wieder höhere Temperaturen kommen. Doch dem ist nicht so. Innerhalb der Schneeglöckchen und Krokusse gibt es auch im Herbst blühende Arten. Rosa Blüten mit sechs Blütenblättern, die direkt am Boden erscheinen, müssen nicht unbedingt Herbstzeitlosen (Colchicum) sein, es gibt auch Krokusse, die in dieser Jahreszeit blühen. Andererseits blühen manche Colchicum-Arten im Frühjahr und werden dann gelegentlich mit Krokussen verwechselt. Crocus und Colchicum sind aber ganz leicht voneinander zu unterscheiden: Colchicum-Blüten enthalten sechs Staubblätter, während es beim Krokus nur drei sind.

\section{Herbst-Schneeglöckchen}

Innerhalb der Schneeglöckchen haben sich zwei Blühzeiten entwickelt, im mediterranen Bereich vor dem Winter und bei uns in Mitteleuropa eine im späten Winter oder Frühling, um die insektenfreie, kalte frühe Winterzeit zu umgehen.

Im Mittelmeergebiet, wo es im Sommer mehrere Monate trocken und heiß ist, wachsen viele Knollen- und Zwiebelpflanzen. Sie überleben diese unwirtliche Zeit mit Hilfe ihrer unterirdischen Überdauerungsorgane (Zwiebeln, Knollen, Rhizome), in denen Wasser und Nährstoffen gespeichert werden.
Vor einigen Jahren blühte in unserem Garten überraschenderweise bereits Mitte Oktober, noch in der warmen Herbstsonne, das Königin-Olga-Schneeglöckchen (Galanthus reginae-olgae, syn. Galanthus nivalis ssp. reginae-olgae, syn. Galanthus praecox). Gleichzeitig erschienen

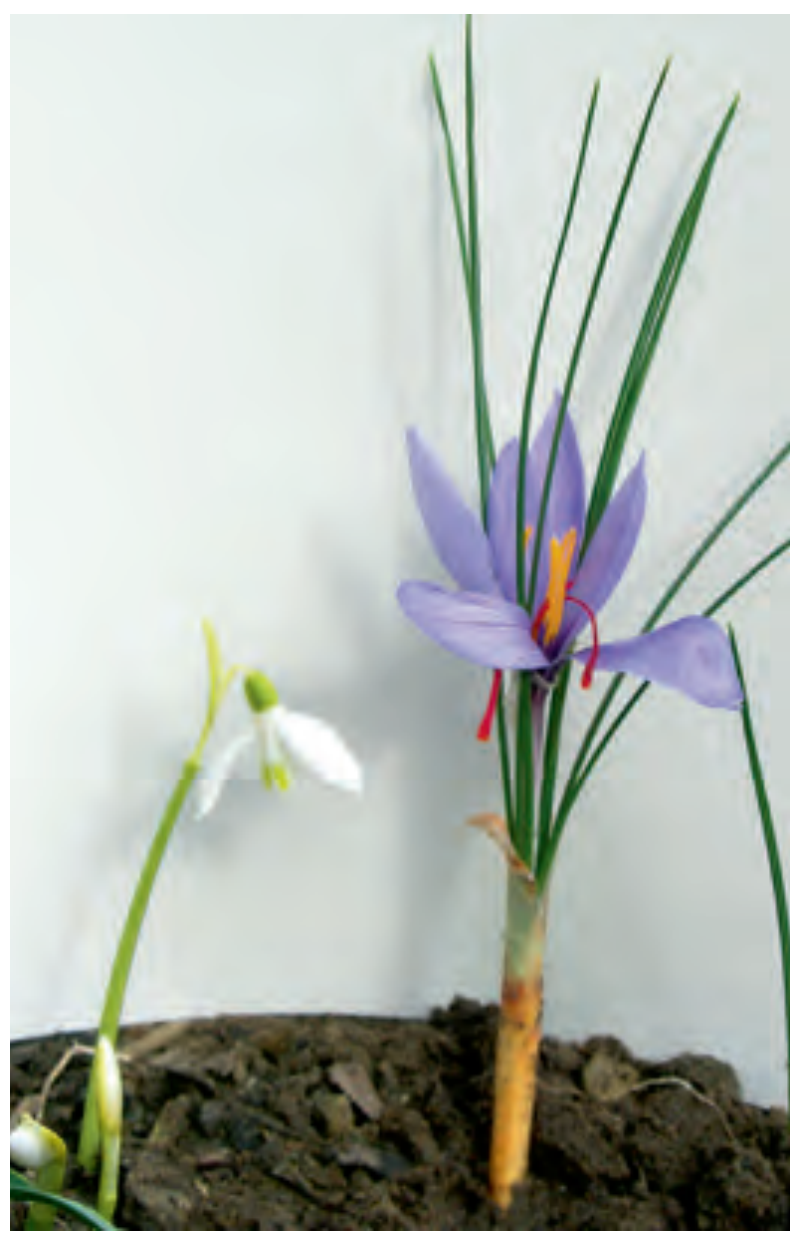

Abb. 1: Ein im Herbst blühendes Schneeglöckchen-Krokus-Paar: Galanthus reginae-olgae und Crocus sativus. (Foto: H. H. Hermanni) 
die hellvioletten Blüten des Safran-Krokus (Crocus sativus).

Da es Mitte Oktober bei uns selten Schnee gibt und oft eine warm-sonnige Witterung herrscht, sollte dieses Schneeglöckchen vielleicht besser Sonnenglöckchen genannt werden. Es wird noch vor dem Winter bestäubt und befruchtet, solange Insekten fliegen. Diese Art kommt in Griechenland, in Montenegro und Nordost-Sizilien in Höhen von 600 bis $1300 \mathrm{~m}$ vor. Im Mittelmeergebiet regnet es vor allem im Winter, dann wachsen die Blätter, betreiben Fotosynthese und werden die Reservestoffe in den unterirdischen Zwiebeln gespeichert.

Das uns bekannte Schneeglöckchen (Galanthus nivalis) treibt seine Blüten im Spätwinter und wird an warmen Tagen durch die ersten Insekten (Bienen, Hummeln) bestäubt. Seine Blätter wachsen vom Winter bis ins späte Frühjahr und führen dann Fotosynthese durch.

Auch im Palmengarten wachsen an verschiedenen Stellen Schneeglöckchen, die durchaus schon im November ihre Blüten zeigen. Eine schöne Gruppe gedeiht in der Nähe der großen Hänge-Buche seitlich des Gesellschaftshauses. Den safranähnlichen Herbstkrokus (Crocus speciosus) gibt es etwa ab September auf verschiedenen Wiesenflächen des Palmengartens zu sehen.

\section{Anschrift des Autors}

Dr. Martin Börnchen, Kastanienweg 17,

48317 Drensteinfurt, E-Mail: boernchen@t-online.de

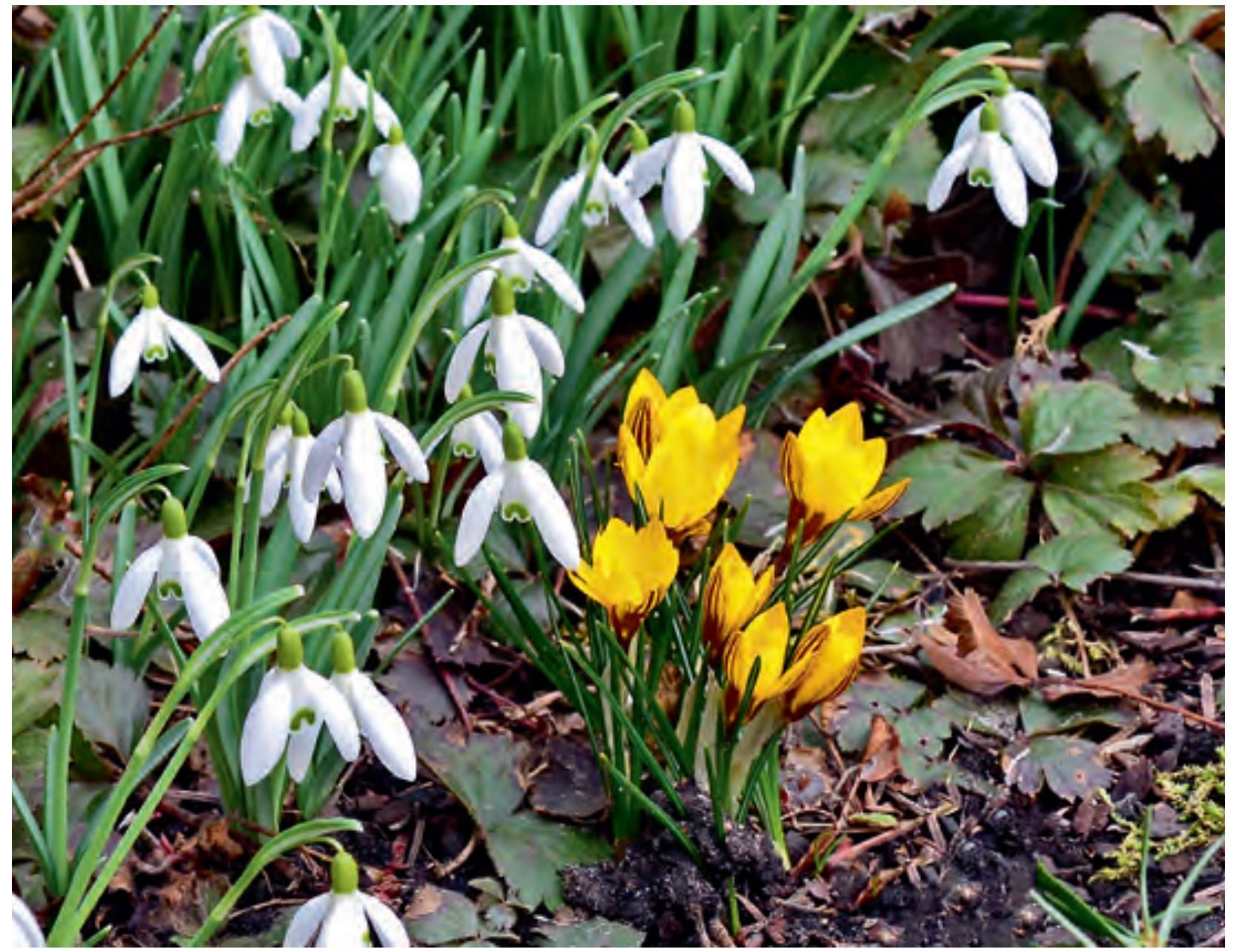

Abb. 2: Ein im Frühling blühendes Schneeglöckchen-Krokus-Paar: Galanthus nivalis und Crocus angustifolius. (Foto: H. H. Hermanni) 